\title{
FOOD DESIGN: UM ESTUDO PARA A MELHORIA DOS HÁBITOS ALIMENTARES INFANTIS
}

Letícia Hilário Guimarães

Universidade do Estado de Minas Gerais

Hg.leticia@gmail.com

Bárbara Maria Martins da Silva

Universidade do Estado de Minas Gerais

babimmaria@gmail.com

Lucas de Castro Santos

Universidade do Estado de Minas Gerais

Idcastro23@gmail.com
Ana Carolina Godinho de Lacerda

Universidade do Estado de Minas Gerais

anacarol_lacerda@hotmail.com

Thalita Barbalho

Universidade do Estado de Minas Gerais

barbalho.thalita@gmail.com

Rita de Castro Engler

Universidade do Estado de Minas Gerais

rcengler@uol.com.br

Resumo: As inovações sociais são compreendidas como uma alternativa para desafios modernos e, aliadas ao design, apresentam a capacidade de atenuar e solucionar problemas complexos, como a obesidade infantil. A vida agitada e o stress colaboram para a deterioração dos padrões alimentares da população. Dessa forma, o consumo de produtos industrializados ricos em gordura, açúcar, sódio e pobre em nutrientes têm aumentado significativamente. As estratégias de marketing, como propagandas, embalagens atraentes e brindes, contribuem ainda mais com esse processo, causando a elevação das taxas de obesidade infantil. O design, nesse cenário, se insere como instrumento eficaz para modificar os atuais hábitos alimentares. Dessa forma o design criativo e estratégico incentiva hábitos mais saudáveis, saindo do campo do produto $\mathrm{e}$ configurando-se como meio capaz de proporcionar qualidade de vida. Baseado nesse entendimento, o projeto tem como proposta solucionar esse problema complexo por meio da visão do Food Design. Compreender o atual contexto da alimentação das crianças, identificar alternativas de alimentos saudáveis e atraentes, e analisar as possibilidades de inserção de novos pratos no contexto dos alunos são objetivos práticos da proposta. A metodologia é caracterizada por pesquisa quanti-qualitativa, em formato de estudo de caso, na Escola Municipal Dr. Cristiano Otoni em Pedro Leopoldo/MG. São desenvolvidas de forma extensionista, oficinas lúdicas, quadro de incentivos e dinâmicas com a comunidade, a fim de minimizar hábitos alimentares não saudáveis. Para viabilizar o projeto, foram realizadas parcerias entre a Escola de Design/UEMG por meio do Centro de Estudos em Design e Tecnologia (CEDTec) e os órgãos competentes do município. Entende-se que $\mathrm{o}$ design pode contribuir para o 
desenvolvimento de comunidades por meio de práticas que visam o bem estar social.

Palavras-chave: Food Design, Obesidade Infantil, Projeto Extensionista, Comunidade de Pedro Leopoldo 